\title{
Between Strategy and Sabotage: A Faux Pas, Technophobia, or Ghanaian Thing?
}

\author{
Stephen Debar Kpinpuo \\ \{skpinpuo@uds.edu.gh\} \\ Department of Management Studies, University for Development Studies, Ghana
}

\begin{abstract}
Ghana's public sector organizations are generally characterized by workplace practices that often seek to sidetrack financial, material, and human resources for purposes other than organizational prosperity. Interestingly, such unethical employee conduct has become the norm, or the 'Ghanaian Thing' (GT). Although this is an affront to effective strategy implementation, researchers have often glossed over its contribution to the continual weakening of public institutions in the country. Using a qualitative study, this paper examined factors of the GT and their impact on strategy execution in four public institutions of Ghana. Findings of the study revealed that strategy-sabotage interface, celebrating sabotage, resistance to change, information hoarding, and 'cash leadership' underlie much of the prevailing organizational ineffectiveness in Ghana. The study further revealed that these GT strategies thrive mainly on organizational disorder. To strengthen Ghana's public institutions, therefore, the five GT enablers must be disabled using appropriate technological interventions.
\end{abstract}

Keywords: Human resource capability, implementation research, public service delivery, strategy, sabotage..

\section{Introduction}

In Ghana, strategic efforts hardly develop beyond the planning phase. In the country's public sector, for example, several well-designed strategies, intended to help sanitize the sector $[1,2$, 3], have ended up either in the shelves of supervising officials [4], or have simply mocked implementation by generating unintended outcomes [5]. Although indigenous strategy implementers have often attributed such failures to inadequate allocation of resources [6], similar projects managed by non-Ghanaians, with similar funding arrangements and terms of reference, are often devoid of these shortcomings [7]. This rhetoric suggests that the Ghanaian worker probably executes strategies other than those specified in organizational roadmaps - a faux pas that is often interestingly justified as a Ghanaian Thing (GT) [8], or unproductive but celebrated workplace practices, including "organizational inertia" [9], dumsorization [10], deliberate resistance to change [11], ineffective communication [12], lack of evaluation and control mechanisms [13], and corruption [14.

This paper interrogates these workplace practices in order not only to provide insight into the ubiquitous incidence of implementation setbacks in Ghana's public sector organizations, but also help create pathways for overcoming the menace. Specifically, the study sought to understand the operations of GT networks, using the nation's Distance Education Program 
(DEP) as a case study. It involved three critical questions: 1) How is the Ghanaian Thing manifested in the implementation of the DEPs? 2) What is its impact on implementation outcomes of the programs? and 3) How may strategy implementation be structured in order to have a $G T$-free process of strategy execution in the country? A careful reflection on these questions will not only help explain recent reports on a high $G T$ prevalence rate in the nation's public institutions, but also help shape business policy implementation in the country. It is thus important to examine the impact of the GT on accomplishment of organizational goals [9, 19] and how public sector operations may be reshaped to reduce GT cases, lessen cost of operation, widen access to products and services, and, consequently, improve general performance of the DEPs. Besides, although many researchers have argued that about 50 to 80 percent of strategic plans fail at the level of implementation [20,21,22], critical implementation issues, such as the GT phenomenon, remain under-researched [23, 24, 25, 26]. In the next section, relevant literature on strategy implementation is reviewed as a subject of two opposing forces: Those pushing for strategic accomplishment and those acting against such strategic efforts. This is followed by data collection methods, presentation, discussion and implication of major findings.

\section{Literature Review}

\subsection{The strategy-sabotage dichotomy}

Naturally, strategy and sabotage are mutually exclusive concepts, as organizational plans are not often designed to be sabotaged. This means that strategy does not really need sabotage to succeed. Interestingly, sabotage sometimes thrives on strategy, particularly at its implementation level [27]. There is empirical evidence to show that strategy implementation is sometimes sabotaged by its very designers and implementers whenever these managers and employees feel that their personal interests are incongruent with certain strategic efforts [28]. Usually, saboteurs emerge whenever there is no consensus amongst strategy implementers [29]. When this happens, a number of strategy executers shamefully morph into saboteurs, creating one of the most difficult challenges an organization can face [9]. Implementation may also be redirected or delayed in the absence of shared understanding [30]. These are all clear instances of sabotage, as they deliberately cause damage to productive capacity. As stated earlier, strategies are to be implemented and not damaged. Certainly, executing or realizing a plan is one thing and damaging or sabotaging the plan is another. Thus, effective strategy implementation and sabotage assume parallel operational functions, and must not be made to interface at any level of strategic thinking. In the next segment, a theoretical framework is used to further explain this dichotomy and to set some parameters for a critical discussion on strategy implementation in Ghana's public sector organizations, in general, and in the country's public distance education programs in particular.

\subsection{Implementation research theories}

Research on strategy implementation can be conducted on any of three core components of implementation, namely factors affecting strategy implementation, the process of strategy implementation, and outcome of the intervention [31]. It may highlight one or a combination of any of these three modules. Accordingly, this research focused on the first kind of implementation research, or "factors affecting strategy implementation" as it sought to identify and examine the GT factors and their impact on implementation of four DEPs in Ghana. For some researchers, different sets of factors must be included in an implementation research. 
These include the content-context-process-outcome framework [32, 33]; an interplay of strategy, organizational structure, and behaviour of the people who make up the organization [34]; inadequate information sharing, unclear responsibility and accountability, and working against the organizational power structure [35]; or organizational culture, communication, clear strategy, execution plan, people competencies, documentation and performance management, change management, CEO involvement, uncertain environment and organization structure [9]. Interestingly, while researchers of these sets of factors generally agree that implementation is affected by these factors, others believe that the impact of some individual factors is more pronounced. These individually poignant factors include leadership style [36, 37], information availability and accuracy [38], organizational structure [39], organizational culture [40], human resources [41, 42], and technology [43]. For reasons of specificity and applicability to the factors under which the GT phenomenon was studied, this research adopted the three-factor framework of Author [44]: leadership, organizational structure, and information systems.

\subsection{Strategy implementation efforts in Ghana}

Ghana is home of great business minds and organizational planners, a human capital that is comparable to, or rather more business-like than most commercial activities in the global business center of New York [45]. However, implementing such bright business plans in the Ghanaian mind has often been a wild goose chase. As the management consultant rightly observed, "Ghana does not lack enterprise [...]; what Ghana lacks is enterprises" (p.7). In the sector of education, for example, as indicated in Fig. 1 below, there is impirical evidence to show that an adoption of a dual mode in the operations of the nation's DEPs, resulted in the programs competing for numbers rather than pursue set goals. Because each program strived to be tagged as a "world bank" of their respective host universities, strategic achievement was not a focus [5].

\begin{tabular}{|c|c|c|c|}
\hline \multicolumn{4}{|c|}{ Phase 1: Objective (What were the Ghanaian DEPs established to accomplish?) } \\
\hline \multicolumn{4}{|c|}{$\begin{array}{l}\text { 1) Increase access to higher education and ensure quality workforce } \\
\text { development, } \\
\text { 2) democratize university education, and } \\
\text { 3) make higher education more affordable }\end{array}$} \\
\hline \multicolumn{4}{|c|}{ Phase 2: Input (What resources were commonly available to the four programs?) } \\
\hline Material Resources & & esources & Financial Resources \\
\hline $\begin{array}{l}\text { use of main center } \\
\text { use of Learning Centers } \\
\text { Program and course offerings } \\
\text { (Pilot online projects) }\end{array}$ & $\begin{array}{l}\text { full-time } \\
\text { part-time } \\
\text { Few adm }\end{array}$ & & $\begin{array}{l}\text { Self-funding } \\
\text { Government? } \\
\text { Loans and grants from donors }\end{array}$ \\
\hline \multicolumn{4}{|c|}{ Phase 3: Program Activities (what activities were commonly followed by all four DEPs?) } \\
\hline \multicolumn{2}{|c|}{ Program Services } & \multicolumn{2}{|c|}{ Participant Responsibilities } \\
\hline \multicolumn{2}{|c|}{$\begin{array}{l}\text { Face-to-face instruction } \\
\text { Distribution of learning modules } \\
\text { Supervision of teaching/learning at LCs } \\
\text { Student evaluation and Certification }\end{array}$} & \multicolumn{2}{|c|}{$\begin{array}{l}\text { Visit LC for face-to-face instruction } \\
\text { Engage in group learning } \\
\text { Complete all course assignments } \\
\text { Pay all participation fees and related expenses }\end{array}$} \\
\hline \multicolumn{4}{|c|}{ Phase 4: Output (What is the result of the interaction between Phases 1 and 2?) } \\
\hline \multicolumn{2}{|c|}{ Cost of Participation } & & Enrollment \\
\hline
\end{tabular}




\begin{tabular}{|c|c|}
\hline $\begin{array}{l}25 \% \text { of program offerings affordable } \\
75 \% \text { of program offerings unaffordable } \\
\text { Sub-degree program fees } 93 \% \text { lower than } \\
\text { bachelor's degree program charges } \\
\text { High transport cost from and to LC \& MC } \\
\text { High hotel Charges (LC \& MC) } \\
\text { Private and commercial internet time charges }\end{array}$ & $\begin{array}{l}25 \% \text { of program offerings accessible } \\
75 \% \text { of program offerings with limited access } \\
90 \% \text { enrollments in Education courses } \\
77 \% \text { enrollments in certificate/diploma } \\
\text { programs } \\
23 \% \text { enrollments in degree programs } \\
\text { Unsatisfactory completion rate }\end{array}$ \\
\hline \multicolumn{2}{|c|}{ Phase 5: Outcome/impact (Are the programs achieving intended results?) } \\
\hline Achievements & Challenges \\
\hline $\begin{array}{l}\text { Affordable non-degree programs } \\
\text { Increased access to non-degree programs } \\
\text { Self-funding programs } \\
\text { Use of part-time instructors }\end{array}$ & $\begin{array}{l}\text { Inadequate resources (material, human, } \\
\text { financial) } \\
\text { Absence of the use of appropriate technology } \\
\text { Unaffordable degree programs } \\
\text { Limited access to degree programs } \\
\text { Unequal distribution of access }\end{array}$ \\
\hline
\end{tabular}

Fig. 1 Implementation of Ghana's DEPs

Source: Kpinpuo, 2013

Interestingly, research on strategy implementation in Ghana is both little and focused on identification of success factors rather than on the interface of strategy and sabotage. For example, Author [54] studied the operational strategies of family businesses in Ghana and found that cost leadership, differentiation strategy and strategic leadership all shape outcome, with strategic leadership as enabler of cost leadership and differentiation strategies. Similarly, authors [6] examined the impact of public policy implementation on performance of state owned enterprises (SOEs) and found that, although public sector organizations in the country have competitive business plans, implementation of such policies was sub-standard. The critical issue of GT-led policy implementation was not addressed, a gap that this research seeks to bridge. In the specific case of distance education programs in Ghana, evaluative studies have been carried out involving the leading two programs [53], a multi-case study of four public universityoperated programs [5], and a teacher education program [13]. In essence, findings of these studies suggested that implementation of distance education strategies was severely hampered. Unlike these research activities, this paper argues that, in Ghana, organizational failures are remotely controlled by an interplay of strategy and sabotage where the latter often outperforms the former through a more formidable and culturally acclaimed network of saboteurs.

\section{Methods}

The purpose of this research was to determine the structure and behavior of the GT network and their impact on strategy implementation in a distance education program in the country. To do so, the study used qualitative approaches and techniques. It involved in-depth interviews with officials of four public university-operated distance education programs. The study purposively selected program officials in the three upper most regions of Ghana - the Upper West, Upper East, and Northern Regions - and granted them in-depth interviews on their experiences and perceptions of the attitude of implementing officials of the distance education programs. The program officials interviewed included four regional representatives of the four programs, four administrative staff at the learning centers and/or regional offices, and eight locally hired tutors, 
bringing the total number of program officials interviewed to 16 . This included 11 males and 5 females from the target administrative regions of Ghana. A semi-structured interview was granted at two levels: First, interviewees were asked questions that allowed them to speak generally and freely about their experiences and convictions about their respective programs, particularly on challenges faced in their attempt to increase access, reduce cost of participation, and equitable distribute access. This provided sufficient ground for further and more focused interrogation on the specific issue of GT network in the second phase of the interview. Here, questions asked centered on interviewees' knowledge, experience, and awareness of GT cases in their respective programs, which they were willing to share. With the consent of all interviewees, the interviews were audio recorded, transcribed, and analyzed.

\section{Findings}

Essentially, findings on general implementation shortfalls corroborated those of previous research outcome. However, some submissions included signals of GT activities and therefore provided good grounds for the second phase of the interview. Examples of such signals included 'poor work attitude', 'connections', 'who you know', 'poor supervision', 'victimization', 'issues of commitment', 'quick money' and 'back door transactions'. The GT-focused interview therefore explored these and other indications and categorized findings under strategy-sabotage interface, celebrating sabotage, undermining the principles of change management, disabling effective information flow, and cash leadership. As explained below, the impact of these different but intertwined GT enablers on strategy implementation is dire.

\subsection{The Strategy-Sabotage Interface}

This research has revealed that strategy implementation in Ghana's public sector organizations is often fiercely contested by sabotage, a core component of the $G T$. The study also revealed that strategy and sabotage are parallel forces that ought not to intersect for successful strategy implementation to occur. In practice, however, both pursuers of strategic plans and implementation saboteurs often find a way to interact for purposes other than organizational wellbeing. Some interviewees spent time explaining how the strategy-sabotage interface (SSI) is created in public institutions. As RR 3 explained,

The organization is a system and it is always difficult for one person to beat this system. I would say everything begins and ends with the bosses. Once a boss compromises his or her authority and agrees with a subordinate to run [sabotage] the system for personal gains, this boss permanently loses the moral authority to discipline the same subordinate if he or she is found in a different wrongdoing. So, the result is a cycle of unsanctionable workplace conduct.

It is interesting that the manager who ought to be superintending over the achievement of strategic goals not only doubles as initiator of GT networks, but also ensures their sustainability. Explaining this further, an interviewee observed that "... a boss can have connections (GT networks) with the accountant, administrator, human resource officer, procurement officer and so on" (Tutor 1); all indications of poor human resource management.

\subsection{Celebrating Sabotage}

Closely related to the issue of SSI is the overwhelming social recognition given to successful organizational saboteurs. This was disclosed by a number of interviewees who stressed that the current organizational climate of Ghana is not conducive for effective strategy implementation. 
One such interviewee argued that "Ghanaians only love to plan, but they don't really care much about the aftermath of their own plans ... and by that I mean, about implementation, evaluation and control issues" (RR 2). Explaining the trend further, Tutor 7 observed that the Ghanaian organizational climate is fundamentally characterized by a certain scramble for $G T$ opportunities, which, the part-time tutor contended, always receive societal and organizational blessings. Tutor 5 offered examples to illustrate these blessings when he remarked that "... as long as society and employees revere people with ...e-e-h... flashy cars, houses, and other material things, even if these people have been unemployed all their life, or are employed but poorly paid, and ... um ... even if such people did not inherit anything from anybody, we will always be looking for quick money [GT possibilities] at work". For this interviewee, therefore, it is the Ghanaian public and some organizational sub-cultures that have created an enabling environment for GT accomplishments.

\subsection{Leading change with the status quo}

Change is Change. It cannot be anything else. It is constant and often requires substantial alterations and, in some cases, a complete overhaul of existing structures. Hosting distance education programs by Ghana's public universities means then that these institutions of higher learning have undertaken to pursue change from a single to a dual mode of educational delivery. This study has however provided evidence that the Ghanaian distance education programs continue to deliver educational services at a distance using the traditional mode. The major difference between the Ghanaian distance education unit and the conventional one is that faculty of distance education programs travel from the main campus to learning centers at different locations throughout the country for face-to-face instruction or to supervise locally hired parttime lecturers. This practice "favors DEP supervisors and cannot change", as Tutor 8 puts it.

\subsection{Information Hoarding}

Effective organizational communication is about creating understanding for the purpose of enhancing workplace performance. On the contrary, pursuers of the GT have often kept vital information away from implementers who need such information to successfully execute management decisions. As the Tutor 2 advised:

Call it information hoarding, if you like, but some information is often kept secret ... why? ... when information is withheld by people who ordinarily should share it with others, then the intent can only be to create confusion amongst organizational members, particularly those noted for their interest in doing the right thing. Clearly, withholding information keeps such people ignorant and easily manipulated. You get what I mean?

Interestingly, the issue of information hoarding was not limited to program officials. There was consensus among interviewees that information flow from management to program participants was also poor. Indeed most of the part-time tutors interviewed indicated that students are often "starved of vital information needed to make their learning experience a good one" (Tutor 1).

\subsection{Cash Leadership}

This research has revealed that the prevalence of the first four GT enablers in Ghanaian organizations is principally necessitated by a grave desire for cash leadership. To the DEP 
official, mere reference to the DEPs as "world banks" marked success, as though they were designed to create world banks. As one program official (RR4) observed,

The program is a promising one, with a very bright future. But current practices seem to place so much emphasis on the financial gains accruing from the program that little attention is paid to the core issue of developing the much needed human resources for the country. You get me? Because education is a social intervention and we need to be careful not to run public educational programs like commercial operations. Otherwise the very purpose for running the programs would be defeated.

Although this is clear indication of a defective implementation that requires some remedial intervention, this research provided no evidence to that effect. Rather, the world banks continue to fund travel and lodge that could be avided with interventions such as online operations.

\section{Discussion, Implication, and Future Research}

The purpose of this research was to identify and examine factors of a GT network in order to determine their impact on strategy implementation in Ghana's public sector organizations, in general, and in public distance education programs, in particular. As may be seen from the findings above, the GT is fundamentally supported by much sabotage, needless resistance to change, information hoarding, and cash leadership. These constructs are characteristically adverse, in nature, and their mere presence in Ghanaian organizations renders these organizations understandably ineffective. For instance, although sabotaging implementation efforts has been found to be one of the most counterproductive things that any organization can experience [28], public organizations in Ghana, such as the distance education programs, have been subjected to considerable levels of sabotage. If, despite their "world bank" status, the Ghanaian programs are experiencing sub-standard performance with regard to augmenting access to degree programs, reducing cost of and democratizing a university education [5], then the programs must be GT embedded. But, should implementation be so GT hindered in a country where organizational effectiveness is required for survival in a highly competitive world? The relevance of this question appears even more pronounced if considered in relation to the works of previous researchers, such as authors [55] and [56], who have observed similar GT attitudes in the management of the country's NGO and private businesses respectively. The seeming consistency in GT manifestation across different sectors of the Ghanaian economy suggests that the phenomenon has become endemic and requires urgent attention.

Another strategy used by GT patrons is needless resistance to change. As Authors [11] have cautioned, people resist change sometimes for various misguiding reasons, including the mere dislike of it, fear of the unknown, loss of friends, comfort, affiliations, and the status quo. Ordinarily, planned change initiatives often seek to trigger vigorous positive organizational transformation using set institutional targets as vehicle for transporting the organization and its members to desired destinations. Interestingly, the Ghanaian worker apparently prefers to realize change (or the desired destination) by pursuing no change.

Besides, for greater access to GT opportunities, organizational members, particularly those committed to the accomplishment of strategic goals, are often kept ignorant by GT experts. Because effective communication and information flow create understanding [58], they are 
generally considered as primary tools for strategy implementers [12]. But, for saboteurs, it is organizational disorder, which they achieve through GT enablers, including information hoarding. Finally, while forward-thinking organizations often adopt differentiation, cost leadership, or a mix of these two operational strategies [54], GT-dominated organizations pursue cash leadership. In $G T$ organizations, leaders and their followers spend so much energy chasing personal monetary interests that little room is created for strategic accomplishment. When organizational leaders develop special interest in, or "social capital" with specific employees, it is either to facilitate strategy implementation [59] or promote $G T$ activities which this research has argued outperform the former. Thus, it can be said that the five GT enablers - the strategysabotage interface, sabotage, leading change for no change, information hoarding, and cash leadership - characteristically determine Ghana's sub-standard performance, particularly in the public sector.

This implies that a GT culture will always undermine strategic accomplishments [60]. This observation is particularly important as research has shown strong ties between corporate culture and organizational performance $[61,62,63]$. While some researchers view organizational culture as having a positive relationship with firm performance in non-African contexts, others have suggested that the collectivist cultural values of Ghana, and the rest of Africa [64], are inconsistent with formal organizational practices [65]. The present research moves beyond this general understanding to providing specific values of the Ghanaian organizational culture (the GT enablers) which do not conform to general organizational norms and practices. One novelty of the research is that it dispels the notion that collectivist cultures like Ghana cannot operate effective organizational systems [66] by suggesting that GT activities are undertaken only by a cross section of members of an organization. A limitation of this research was that it kept a focus only on GT trends in four DEPs, as experienced by operators of the programs in three of Ghana's ten administrative regions. Future studies in the area could consider other public institutions both in Ghana and the rest of Africa.

\section{Conclusion}

Strategy implementation in Ghana is as complex as it is intriguing. It is complex because, whereas strategic plans elsewhere are easily transformed into various implementation outcomes, similar, or rather, better strategies in Ghana often result in unintended consequences. In the same comparative vein, strategy implementation can be perplexing as most organizational activities represent a departure from implementation ethics. First, sabotage, rather than implementation plans, drives most execution activities. Through a network of saboteurs, sabotage ensures that strategic accomplishment is illusive. Second, because most operations target outcomes other than organizational prosperity, the Ghanaian implementer pursues change only by maintaining the status quo. Third, employees, particularly those interested in strategic accomplishment, are ritually denied access to any piece of information that is capable of providing legal impetus for questioning the unethical behavior of saboteurs. Fourth, leadership, at all levels of the organization, has representatives working to protect sabotage rather than organizational interests. Since most unethical conducts are often intended to create opportunities for management and employees to divert financial resources of the employer, leaders who safeguard sabotage at the workplace may be viewed as providing cash leadership 


\section{References}

[1] Hood, C.: The New Public Management in the 1990s: Variations on a Theme. Accounting Organisations and Society, Vol. 20, No. 2/3, pp. 93-109 (1995)

[2] Lapsley, I.: The NPM Agenda: Back to the Future. Financial Accountability \& Management, Vol. 24, No. 1, pp. 442477-96 (2008)

[3] Page, S.: What is new about the new public management? Administration Change in the Human Services. Public Administrative Review, Vol. 65, No. 6, pp. 713-727 (November/December 2005)

[4] Olsen, E. M., Slater, S. F., Hult, T.M.: The importance of structure and process to strategy implementation, Business Horizons 48, 47-54 (2005)

[5] Kpinpuo, S. D.: Assessing the Effectiveness of Distance Education in Ghana: A Multi-site Case Study. Ph.D. Dissertation, Purdue University, Indiana - USA (2013)

[6] Simpson, S. N. Y. \& Buabeng, T.: Performance contract and performance of public enterprises: A study of the implementation processes. Journal of Public Administration and Governance, Vol. 3, No. 2 (2013)

[7] Ghana Business News: Government intensifies moves to put ECG on concession. Retrieved October 8, 2016 from https://www.ghanabusinessnews.com/2016/04/19/governmentintensifies-moves-to-put-ecg-on-concession/ (2016)

[8] Joy News: Corruption allegation against two deputy chiefs of staff. Joy NewsFile, Accra Ghana (2017)

[9] Alamsjah, F.: Key Success Factors in Implementing Strategy: Middle Level Managers' Perspectives. Procedia Social and Behavioral Sciences, Vol. 24, pp. 1444-1450 (2011)

[10] Lumumba, P. L. O. 2015. Good Governance: Wither Africa? Paper presented at the PAVA Memorial Forum, August 28, 2015, Accra - Ghana.

[11] Palmer, I., Dunford R. \& Akin, G.: Managing Organizational Change: A Multiple Perspectives Approach. McGraw-Hill, Asia (2009)

[12] Hughes, R. L., Ginnet, R. C., \& Curphy, G. J.: Leadership: Enhancing the lessons of experience. McGraw-Hill/Irwin: New York (2012)

[13] Sampong, K. A.: An evaluative study of a distance teacher education program in a university in Ghana. Internation Review of Research in Open and Distance Learning, Vol. 10, No. 4, pp. 1-25 (2009)

[14] Bratton, M. \& Van de Walle, N.: Neopatrimonial regimes and political transitions in Africa. World Politics, Vol. 46, No. 4 (1994) 
[20] Ashkenas R. \& Francis S.: Integration managers: Special leaders for special times. Harvard Business Review, Vol. 78, No. 6, pp. 108-116 (2000)

[21] Raps, A.: Implementing strategy. Strategic Finance, 85(12), pp. 48-53 (2004)

[22] Atkinson, H.: Strategy implementation: a role for the balanced scorecard? Management Decision, Vol. 44 No. 10, pp. 1441-1460 (2006)

[23] Basu P.K.: Reinventing Public Enterprises and Their Management as the Engine Of Development and Growth. In United Nations Publication, Public Enterprises: Unresolved Challenges and New Opportunities, ST/ESA/PAD/SER.E/69, United Nation. New York, pp. 920 (2007)

[24] Chang, H.: State-Owned Enterprise Reform, Policy Note, United Nations Department for Economic and Social Affairs (UNDESA), New York (2007)

[25] Uddin S. \& Tsamenyi M.: Public Sector Reforms and the Public Interest: A Case Study Of Accounting Control Changes And Performance Monitoring In A Ghanaian State-Owned Enterprisell. Accounting, Auditing And Accountability Journal, Vol. 18, No. 5, pp. 648-74 (2005)

[26] World Bank: Bureaucrats in Business: The Economics and Politics of Government. World Bank Policy Research Report, Washington DC (1995)

[27] Rapert, M. I., Velliquette, A., Garretson, J. A.: The strategic implementation process: Evoking strategic consensus through communication. Journal of Business Research, Vol. 55, pp. 301-310 (2002)

[28] Guth, W. D. \& MacMillan I. C.: Strategy implementation versus middle management selfinterest. Strategic Management Journal, Vol. 7, pp. 313-327 (1986)

[29] Noble, C. H.: Building the Strategy Implementation Network, Business Horizons, November- December (1999)

[30] Beer, M., Eisenstat, R. A.: The Silent Killers of Strategy Implementation and Learning. Sloan Management Review Summer (2000)

[31] Peters, D. H., Adam, T., Olonge, O., Agyepong I. A. \& Tran, N.: Implementation research: What it is and how to do it. BMJ, doi: 10.1136/bmj.f6753 (2013)

[32] Okumus, F.: Towards a strategy implementation framework. International Journal of Contemporary Hospitality Management; 13 (7): 327-338 (2001)

[33] Okumus, F.: A framework to implement strategy in organizations, Management Decision; 41 (9): 871-882 (2003)

[34] Brinkschröder, A.: Strategy implementation: Key factors, challenges and solutions. $4^{\text {th }}$ IBA thesis conference, November 6th, 2014, Enschede, The Netherlands. 
[35] Herbniak, L.G.: Obstacles to effective strategy implementation. Organizational Dynamics, Vol. 35, No.1, pp. 12-31 (2006)

[36] Cater, T., \& Pucko, D.: Factors of effective strategy implementation: Empirical evidence from Slovenian business practice. Journal for East European Management Studies, Vol. 15, No. 3, pp. 207-236 (2010)

[37] Zaribaf, M., \& Bayrami, H.: An effective factors pattern affecting implementation of strategic plans. Academic and Business Research Institute (2010)

[38] Lingard, H., Francis, V., \& Turner, M.: Work-life strategies in the Australian construction industry: Implementation issues in a dynamic project-based work environment. International Journal of Project Management, Vol. 30, No. 3, pp. 282-295 (2012)

[39] Carlopio, J., \& Harvey, M.: The Development of a Social Psychological Model of Strategy Implementation, International Journal of Management, Vol. 29, No. 3, pp. $75-85$ (2012)

[40] Ke, W., \& Wei, K. K.: Organizational learning process: its antecedents and consequences in enterprise system implementation. Journal of Global Information Management, Vol. 14, No. 1, pp. 1-22 (2006)

[41] Fulmer, W.E.: Human resources management: the right hand of strategy implementation, Human Resources Planning, Vol. 13, No. 1, pp. 1-11(1990)

[42] Lorange, P.: Strategy implementation: The new realities, in: Long Range Planning, Vol. 31, No. 1, pp. 18-29 (1998)

[43] Leonardo, P. M.: Materializing Strategy: The blurry line between strategy formulation and strategy implementation. British Journal of Management, Vol. 26, pp. 17-21 (2015) DOI: $10.1111 / 1467-8551.12077$

[44] Rajasekar, J.: Factors affecting effective strategy implementation of electricity distribution companies in the Sultanate of Oman. International Journal of Bsiness and Social Science. Vol. 5, No. 9(1); pp. 169-183 (August 2014)

[45] Mintzberg, H.: Developing Leaders? Developing Countries? Development in Practice, Vol. 16, No. 1 (2006)

[54] Agyapong, A. \& Boamah, R. B.: Business Strategies and Competitive Advantage of Family Hotel Businesses in Ghana: The Role of Strategic Leadership. The Journal of Applied Business Research, Vol. 29, No. 2, (2003)

[55] Kpinpuo, S. D. \& Sanyare, F.: Enhancing NGO Management in Ghana: An Alternative Approach. Developing Country Studies, Vol. 5, No. 4 (2015)

[56] Arthur, P.: The State, Private Sector Development, and Ghana's "Golden Age of Business". African Studies Review, Vol. 49, No. 1, pp. 31-50 (2006) 
[57] Stewart, L. G. \& Brown, G. K.: Human Resource Management: Linking strategy to practice. Danvers: John Wiley \& Sons, Inc. (2009)

[58] Diedong, A. L.: Responsible Journalism and Quest for Professional Standards in Ghana. Woeli Publishing Services, Accra (2016)

[59] Acquaah, M.: Managerial social capital, strategic orientation, and organizational performance in an emerging economy. Strategic Management Journal 28, pp. 1235-1255 (2007)

[60] Kpinpuo, S.: Solutions to Africa's development challenges. In B. House-Soremekun and T. Falola (Eds.), Globalization and sustainable development in Africa. New York: University of Rochester Press (2011)

[61] Ostroff, C.,Kinicki, A. J., \&Tankins, M. M.: Organizational culture and climate. In W. C. Borman, D.R. Ilgen, R. J.Klimoski,\& I.Weiner (Eds.), Handbook of psychology, pp. 565-593, Hoboken, NJ:Wiley (2003)

[62] Wilderom, C. P. M., Glunk, U., \& Maslowski, R.: Organizational culture as a predictor of organizational performance. In N. M. Ashkanasy, C. P. M. Wilderom, \& M. F. Petersen (Eds.). Organizational culture and climate. Thousand Oaks, CA: Sage (2000)

[63] Zhang, M., Yang, B., \& Li, H.: Linking organizational culture with performance: The mediating role of human resource capability and moderating role of environmental uncertainty. Paper presented at the Chinese-Hungarian International Conference Economic of Crisis, Education and Labor, June 30-July 1, 2011, Budapest.

[64] Hofstede, G., Neuijen, B., Ohayv, D. D., \& Sanders, G.: Measuring organizational cultures: A qualitative study across twenty cases. Administrative Science Quarterly, No. 35, pp. 286250 (1990) doi: $102307=2393392$

[65] Dia, M.: Africa's management in the 1990s and beyond: Reconciling indigenous and transplanted institutions. Washington, DC: The World Bank (1996)

[66] Dadzie, C. A., Winston, E.M. \& Dadzie K. Q.: Organizational culture, competitive strategy, and performance in Ghana. Journal of African Business, Vol. 13, No. 3, pp. 172-182, DOI: $10.1080 / 15228916.2012 .727737$ (2012) 